\title{
Mast cells in asthma: biomarker and therapeutic target
}

\author{
Laurent L. Reber ${ }^{1,2}$ and John V. Fahy $3,4,5,6,7$
}

Affiliations: 'Département d'Immunologie, Unité des Anticorps en Thérapie et Pathologie, Institut Pasteur, Paris, France. ${ }^{2}$ Institut National de la Santé et de la Recherche Médicale (INSERM), U1222, Paris, France. ${ }^{3}$ The Airway Clinical Research Center, University of California, San Francisco, CA, USA. ${ }^{4 D i v i s i o n ~ o f ~ P u l m o n a r y ~}$ and Critical Care Medicine, University of California, San Francisco, CA, USA. ${ }^{5}$ Cardiovascular Research Institute, University of California, San Francisco, CA, USA. ${ }^{6}$ Sandler Center for Basic Asthma Research, University of California, San Francisco, CA, USA. ${ }^{7}$ Dept of Medicine, University of California, San Francisco, CA, USA.

Correspondence: Laurent L. Reber, Département d'Immunologie, Unité des Anticorps en Thérapie et Pathologie, INSERM U1222, Institut Pasteur, 25 rue du Docteur Roux, 75015 Paris, France.

E-mail: laurent.reberapasteur.fr

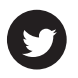

$@$ ERSpublications

Mast cell numbers or activity levels could help identify asthma subtypes and be relevant for treatment effectiveness http://ow.ly/Xmanp

The heterogeneity of asthma phenotypes represents a challenge for adequate assessment and treatment of the disease [1]. The molecular analysis of highly characterised cohorts of asthma patients should help to identify biomarkers of asthma subtypes, which might lead to more efficient and personalised therapies for asthma [1,2]. So far, asthma has been mainly divided into two subtypes: T-helper cell type 2 (Th2)-high asthma, which comprises patients with airway and systemic eosinophilia who are responsive to glucocorticoids; and Th2-low asthma, which comprises patients without airway or systemic eosinophilia who are not responsive to glucocorticoids [3]. Besides eosinophilia, patients with Th2-high asthma have other signs of airway type 2 inflammation, including increased numbers of airway mast cells [4].

Many phenotypic characteristics of mast cells can be modulated by genetic and environmental factors, including changes in the microenvironment associated with the progression of a disease [5]. Despite such phenotypic plasticity, mast cells have been generally subcategorised into two groups based on the protease content of their cytoplasmic granules: $\mathrm{MC}_{\mathrm{T}}$, which express high levels of tryptase but little or no chymase; and $\mathrm{MC}_{\mathrm{TC}}$, which express both tryptase and chymase $[6,7]$ as well as cathepsin $\mathrm{G}$ and carboxypeptidase $\mathrm{A} 3$ (CPA3) $[8,9]$. While $\mathrm{MC}_{\mathrm{TC}}$ are predominantly found in connective tissues, such as the skin, $\mathrm{MC}_{\mathrm{T}}$ are found at mucosal sites and represent the majority ( $90 \%)$ of lung mast cells. $\mathrm{MC}_{\mathrm{T}}$ are found in the bronchial/bronchiolar lamina propria and alveoli [10], and low numbers of $\mathrm{MC}_{\mathrm{TC}}$ can be found beneath the epithelium in the lamina propria and submucosa, in close proximity to submucosal glands, and around the airway smooth muscle layers of major bronchi [11].

Gene expression analysis of airway epithelial brushings has identified two mast cell-specific protease genes (the tryptase TPSAB1 and CPA3) among the top 10 most differentially expressed genes in asthmatic versus control subjects [12]. A follow-up study further revealed that among asthmatics, patients with Th2-high asthma have significantly higher intraepithelial mast cell numbers in the airways than patients in the Th2-low group, and that such intraepithelial mast cells display a unique phenotype with expression of

Received: Jan 102016 | Accepted: Jan 112016

Support statement: L.L. Reber is the recipient of a Marie Skłodowska-Curie Individual Fellowship (H2020-MSCA-IF-2014 656086) from the European Commission and acknowledges support from the French Institut National de la Santé et de la Recherche Médicale (INSERM). J.V. Fahy acknowledges support from National Institutes of Health (National Heart, Lung, and Blood Institute) grants HL109146 and HL107202 and the Sandler Center for Basic Asthma Research. Funding information for this article has been deposited with FundRef.

Conflict of interest: Disclosures can be found alongside the online version of this article at erj.ersjournals.com

Copyright OERS 2016 
tryptase and CPA3 but not chymase [4]. Importantly, expression of tryptase and CPA3 in epithelial brushings was associated with responsiveness to glucocorticoids [4], which reveals that such mast cell-specific proteases represent potential biomarkers of asthma subtypes. However, the molecular phenotyping method used in that study to identify mast cell protease genes required bronchoscopic samples, and therefore has limited applicability in the clinic [4].

One approach that could be more broadly applicable is the analysis of gene expression in induced sputum [13]. In this issue of the European Respiratory Journal, WANG et al. [14] demonstrate that gene expression for tryptase and CPA3 can be detected in induced sputum cells from asthmatics. The authors defined three groups of patients: one without significant levels of mast cell protease gene expression, a second in which only tryptase could be detected $\left(\mathrm{MC}_{\mathrm{T}}\right)$ and a third with significant expression of both tryptase and $\mathrm{CPA3}$ genes (which they named $\mathrm{MC}_{\mathrm{T} / \mathrm{CPA} 3}$ ). Chymase expression was low in all three groups, suggesting that luminal mast cells also have the same unusual protease phenotype (tryptase and CPA3 high and chymase low [13]) that is found in intraepithelial mast cells in Th2-high asthma [4]. These results for chymase are also in agreement with a previous report, which also identified tryptase and CPA3 gene expression in induced sputum cells from asthmatics [13]. In the present report, WANG et al. [14] confirm and extend these results by showing that the " $\mathrm{MC}_{\mathrm{T} / \mathrm{CPA} 3}$ " subtype has elevated exhaled nitric oxide fraction, sputum eosinophils, bronchial sensitivity and reactivity compared with the " $\mathrm{MC}_{\mathrm{T}}$ " subtype. In addition, the authors report that the " $\mathrm{MC}_{\mathrm{T} / \mathrm{CPA} 3}$ " subtype had better clinical response to corticosteroid treatment.

A limitation of the current study by WANG et al. [14] is the absence of quantification and characterisation of mast cells in sputum by immunohistochemistry. Although present at very low levels, mast cells have been detected in induced sputum of asthmatics in two previous studies $[15,16]$. Both studies also noted that basophils were present in sputum from asthmatics (and at higher numbers than mast cells). Circulating basophils express tryptase, albeit at much lower levels $(<1 \%)$ than that found in tissue-resident mast cells $[15,17,18]$. In addition, recent studies in mice showed that some levels of CPA3 promoter activity can be detected in basophils [19,20]; whether this is also the case in human basophils is unknown. Together, these results raise the possibility that the tryptase and CPA3 gene expression that is detectable in induced sputum might originate from basophils rather than mast cells.

The finding that higher gene expression for both tryptase and CPA3 in induced sputum is associated with eosinophilic asthma and responsiveness to glucocorticoids is clinically relevant for at least two reasons. The first reason is the possibility that mast cell genes could be measured as a biomarker of Th2-high asthma or of responsiveness to corticosteroids. The problem here is that measuring gene expression in induced sputum cells is relatively complex and is ill-suited as a test in a patient care environment. A more feasible biomarker strategy would be blood-based measures of mast cell proteases, but further study is necessary to determine how well blood measures of tryptase or CPA3 reflect airway measures. The second reason is the possibility that mast cells (or basophils) orchestrate type 2 immune responses in the airway, i.e. that they are upstream rather than downstream of type 2 cytokine activity. Specifically, it is possible that mast cells or basophils are important cellular sources of the type 2 cytokines that cause the airway eosinophilia in Th2-high asthma. In this scenario, the work of WANG et al. [14] provides rationale for considering mast cells and basophils as cellular targets to treat Th2-high asthma.

\section{References}

1 Wenzel SE. Asthma phenotypes: the evolution from clinical to molecular approaches. Nat Med 2012; 18: 716-725.

2 Wagener AH, Yick CY, Brinkman P, et al. Toward composite molecular signatures in the phenotyping of asthma. Ann Am Thorac Soc 2013; 10: Suppl., S197-S205.

3 Fahy JV. Type 2 inflammation in asthma - present in most, absent in many. Nat Rev Immunol 2015; 15: 57-65.

4 Dougherty RH, Sidhu SS, Raman K, et al. Accumulation of intraepithelial mast cells with a unique protease phenotype in $\mathrm{T}_{\mathrm{H}}$ 2-high asthma. J Allergy Clin Immunol 2010; 125: 1046-1053.

5 Galli SJ, Kalesnikoff J, Grimbaldeston MA, et al. Mast cells as "tunable" effector and immunoregulatory cells: recent advances. Annu Rev Immunol 2005; 23: 749-786.

6 Irani AM, Bradford TR, Kepley CL, et al. Detection of MCT and MCTC types of human mast cells by immunohistochemistry using new monoclonal anti-tryptase and anti-chymase antibodies. $J$ Histochem Cytochem 1989; 37: 1509-1515.

$7 \quad$ Li L, Meng XW, Krilis SA. Mast cells expressing chymase but not tryptase can be derived by culturing human progenitors in conditioned medium obtained from a human mastocytosis cell strain with c-kit ligand. J Immunol 1996; 156: 4839-4844.

8 Gibson PG, Allen CJ, Yang JP, et al. Intraepithelial mast cells in allergic and nonallergic asthma. Assessment using bronchial brushings. Am Rev Respir Dis 1993; 148: 80-86.

9 Djukanovic R, Wilson JW, Britten KM, et al. Quantitation of mast cells and eosinophils in the bronchial mucosa of symptomatic atopic asthmatics and healthy control subjects using immunohistochemistry. Am Rev Respir Dis 1990; 142: 863-871.

10 Irani AA, Schechter NM, Craig SS, et al. Two types of human mast cells that have distinct neutral protease compositions. Proc Natl Acad Sci USA 1986; 83: 4464-4468. 
11 Matin R, Tam EK, Nadel JA, et al. Distribution of chymase-containing mast cells in human bronchi. J Histochem Cytochem 1992; 40: 781-786.

12 Woodruff PG, Boushey HA, Dolganov GM, et al. Genome-wide profiling identifies epithelial cell genes associated with asthma and with treatment response to corticosteroids. Proc Natl Acad Sci USA 2007; 104: 15858-15863.

13 Peters MC, Mekonnen ZK, Yuan S, et al. Measures of gene expression in sputum cells can identify TH2-high and TH2-low subtypes of asthma. J Allergy Clin Immunol 2014; 133: 388-394.

14 Wang G, Baines KJ, Fu JJ, et al. Sputum mast cell subtypes relate to eosinophilia and corticosteroid response in asthma. Eur Respir J 2016; 47: 1123-1133.

15 Foresi A, Leone C, Pelucchi A, et al. Eosinophils, mast cells, and basophils in induced sputum from patients with seasonal allergic rhinitis and perennial asthma: relationship to methacholine responsiveness. J Allergy Clin Immunol 1997; 100: 58-64.

16 Gauvreau GM, Lee JM, Watson RM, et al. Increased numbers of both airway basophils and mast cells in sputum after allergen inhalation challenge of atopic asthmatics. Am J Respir Crit Care Med 2000; 161: 1473-1478.

17 Foster B, Schwartz LB, Devouassoux G, et al. Characterization of mast-cell tryptase-expressing peripheral blood cells as basophils. J Allergy Clin Immunol 2002; 109: 287-293.

18 Jogie-Brahim S, Min HK, Fukuoka Y, et al. Expression of alpha-tryptase and beta-tryptase by human basophils. J Allergy Clin Immunol 2004; 113: 1086-1092.

19 Feyerabend TB, Weiser A, Tietz A, et al. Cre-mediated cell ablation contests mast cell contribution in models of antibody- and T cell-mediated autoimmunity. Immunity 2011; 35: 832-844.

20 Lilla JN, Chen CC, Mukai K, et al. Reduced mast cell and basophil numbers and function in Cpa3-Cre; Mcl-1fl/fl mice. Blood 2011; 118: 6930-6938. 